\title{
Combined treatment of drug-resistant tuberculosis with bedaquiline and delamanid: a systematic review
}

\author{
To the Editors:
}

The World Health Organization (WHO) estimated that 490000 cases of multidrug-resistant (MDR) tuberculosis (TB) (defined as TB caused by Mycobacterium tuberculosis strains resistant to at least isoniazid and rifampicin) occurred in 2016. Among them, $\sim 6.2 \%$ had extensively drug-resistant (XDR) TB (i.e. TB caused by MDR strains with additional resistance to fluoroquinolones and at least one second-line injectable drug) [1].

An appropriate pharmacological regimen can bacteriologically and clinically cure, and prevent the emergence and spread of further resistances. However, the management of MDR- and other chronic TB cases can be clinically challenging, as well as raise public health concerns, in patients with limited treatment options. An insufficient number of active drugs during both intensive and continuation phases cannot allow the patient to be saved, while creating further resistance [2].

Due to this reason, to date, the overall success rate for MDR-TB is less than $60 \%$, and is lower than $40 \%$ for XDR-TB [1].

Furthermore, the incidence of adverse events can be particularly high when administering anti-MDR-TB drugs [2-6].

The recent availability of bedaquiline and delamanid could positively affect poor treatment outcomes of MDR-TB cases, reduce the occurrence of adverse events, and halt further drug resistance and transmission.

Bedaquiline is effective and safe, even if increased QT interval and cardiac complications have been recorded [3-7].

Delamanid-containing regimens can achieve treatment success in up to $80 \%$ of MDR/XDR-TB cases, with limited adverse events, such as prolonged QT interval and emesis $[4,8]$.

The WHO does not recommend combination of bedaquiline and delamanid. owing to a potential high risk of cardiac toxicity [9]; however, in difficult-to-treat MDR/XDR-TB cases, where pharmacological alternatives to design a regimen with four active drugs are not available, bedaquiline and delamanid combined treatment, in addition to optimised background regimen, was proposed as a life-saving option [10, 11].

The aim of the present study was to perform a systematic review on the efficacy and safety of co-administered bedaquiline and delamanid in MDR-TB patients.

Peer-reviewed articles written in English reporting on efficacy/effectiveness, safety, and tolerability of individualised regimens containing both bedaquiline and delamanid in patients with culture- and drug susceptibility testing (DST)-confirmed MDR/XDR-TB were selected.

PubMed and Embase were used to identify any relevant manuscripts published up until May 8, 2018, excluding editorials, reviews, experimental studies on animal models, manuscripts describing TB patients recruited without a confirmed bacteriological diagnosis, and conference abstracts (because of limited available information).

Cite this article as: Pontali E, Sotgiu G, Tiberi S, et al. Combined treatment of drug-resistant tuberculosis with bedaquiline and delamanid: a systematic review. Eur Respir J 2018; 52: 1800934 [https://doi.org/ 10.1183/13993003.00934-2018]. 
TABLE 1 Summary of the findings in six studies reporting on delamanid and bedaquiline combination treatment to manage 87 multidrug-resistant (MDR)/extensively drug-resistant (XDR) tuberculosis (TB) cases

\begin{tabular}{|c|c|c|c|c|c|c|c|c|c|c|c|c|c|}
\hline $\begin{array}{l}\text { First author, } \\
\text { publication } \\
\text { year }\end{array}$ & Countries & $\begin{array}{l}\text { Patients n } \\
\left(\% \mathrm{HIV}^{+}\right)\end{array}$ & $\begin{array}{l}\text { Pre-treated } \\
\text { for TB }\end{array}$ & MDR-TB cases & XDR-TB cases & $\begin{array}{l}\text { Use of the two } \\
\text { drugs }\end{array}$ & $\begin{array}{l}\text { Concomitant QTC } \\
\text { prolonging } \\
\text { drugs }\end{array}$ & $\begin{array}{l}\text { Patients } \\
\text { taking one } \\
\text { or both } \\
\text { drugs for } \\
\text { more than } \\
24 \text { weeks }\end{array}$ & $\begin{array}{l}\text { Median } \\
\text { exposure to } \\
\text { BDQ/DLM } \\
\text { combination } \\
\text { treatment }\end{array}$ & $\begin{array}{l}\text { BDQ and/or DLM } \\
\text { discontinuations }\end{array}$ & QTC & $\begin{array}{l}\text { Sputum } \\
\quad \text { culture } \\
\text { conversion }\end{array}$ & $\begin{array}{l}\text { Outcome/ } \\
\text { evaluable } \\
\text { outcome }\end{array}$ \\
\hline $\begin{array}{l}\text { LACHÂTRE [11], } \\
2016\end{array}$ & France & $1(0 \%)$ & $1(100 \%)$ & 0 & $1(100 \%)$ & $\begin{array}{l}0 \text { sequential } \\
1(100 \%) \\
\text { concomitant }\end{array}$ & None & Not specified & Not specified & $\begin{array}{l}0 \text { for non-cardiac } \\
\text { adverse events } \\
0 \text { for cardiac adverse } \\
\text { events }\end{array}$ & $\begin{array}{l}0 \text { with }>60 \mathrm{~ms} \\
\text { increase } \\
0 \text { with }>500 \mathrm{~ms}\end{array}$ & Not specified & $\begin{array}{l}\text { Favourable } \\
\text { outcome (but } \\
\text { not further } \\
\text { specified) }\end{array}$ \\
\hline $\begin{array}{l}\text { MARYANDISHEV } \\
\text { [12], } 2017\end{array}$ & $\begin{array}{l}\text { India, Russian } \\
\text { Federation, } \\
\text { the } \\
\text { Netherlands }\end{array}$ & $5(0 \%)$ & $5(100 \%)$ & 0 & $5(100 \%)$ & $\begin{array}{l}0 \text { sequential } \\
5(100 \%) \\
\quad \text { concomitant }\end{array}$ & $\begin{array}{l}3 \text { patients CFZ } \\
\text { (60\%) } \\
1 \text { patient MFX } \\
\text { (20\%) } \\
1 \text { patient CFZ + } \\
\text { MFX (20\%) }\end{array}$ & $1(20 \%)$ & $\begin{array}{l}168 \text { days (range } \\
155-427)\end{array}$ & $\begin{array}{l}0 \text { for non-cardiac } \\
\text { adverse events } \\
0 \text { for cardiac adverse } \\
\text { events }\end{array}$ & $\begin{array}{l}>60 \mathrm{~ms} \text { increase not } \\
\text { reported } \\
2 \text { with }>500 \mathrm{~ms} \\
(520 \mathrm{~ms} \text { at week } \\
16 \text { in one patient; } \\
509 \mathrm{~ms} \text { at weeks } \\
5 \text { and } 9 \text { in one } \\
\text { patient) }\end{array}$ & $3 / 5(60 \%)$ & $\begin{array}{l}1 \text { cured } \\
3 \text { culture converted } \\
1 \text { died (respiratory } \\
\text { insufficiency) }\end{array}$ \\
\hline $\begin{array}{l}\text { GUGLLLMETTI } \\
\text { [13], } 2018\end{array}$ & France, Latvia & $10(0 \%)$ & $\begin{array}{l}\text { Information } \\
\text { not } \\
\text { available }\end{array}$ & $\begin{array}{l}4 \mathrm{MDR}+\mathrm{FLQs} \\
\text { resistant } \\
(40 \%)\end{array}$ & $6(60 \%)$ & $\begin{array}{l}4(40 \%) \text { sequential } \\
\text { (BDQ followed } \\
\text { by DLM) } \\
\text { because of } \\
\text { BDQ resistance } \\
6(60 \%) \\
\text { concomitant }\end{array}$ & $\begin{array}{l}3 \text { patients CFZ } \\
\text { (30\%) } \\
1 \text { patient MFX } \\
(10 \%) \\
4 \text { patients CFZ + } \\
\text { MFX (40\%) }\end{array}$ & $\begin{array}{c}6(60 \%) \text { BDQ } \\
\text { laverage } \\
391 \text { days) } \\
9(90 \%) \text { DLM } \\
\text { laverage } \\
532 \text { days) }\end{array}$ & $\begin{array}{c}171 \text { days (IQR } \\
\text { 138-327) }\end{array}$ & $\begin{array}{l}0 \text { for non-cardiac } \\
\text { adverse events } \\
0 \text { for cardiac adverse } \\
\text { events }\end{array}$ & $\begin{array}{l}0 \text { with }>60 \mathrm{~ms} \\
\text { increase } \\
2 \text { with }>500 \mathrm{~ms} \text { (both } \\
\text { reverted after } \\
\text { discontinuation of } \\
\text { a companion } \\
\text { drug, CFZ and } \\
\text { MFX, respectively) }\end{array}$ & $8 / 8(100 \%)$ & $\begin{array}{l}9 \text { cured } \\
1 \text { lost to follow up } \\
\text { (last culture } \\
\text { negative) }\end{array}$ \\
\hline Монг [8], 2018 & South Africa & $\begin{array}{l}32 \text { (some, } \\
\text { but not } \\
\text { specified) }\end{array}$ & $\begin{array}{l}\text { Information } \\
\text { not } \\
\text { available }\end{array}$ & $\begin{array}{l}\text { Not specified: } \\
\text { all patients } \\
\text { were RR-TB } \\
\text { and beyond }\end{array}$ & $\begin{array}{l}\text { Not specified: } \\
\quad \text { all patients } \\
\text { were } \\
\text { RR-TB and } \\
\text { beyond }\end{array}$ & $\begin{array}{l}\text { Information not } \\
\text { available }\end{array}$ & $\begin{array}{l}24 \text { patients CFZ } \\
(75 \%)\end{array}$ & $\begin{array}{l}\text { Occurred, but } \\
\text { it was not } \\
\text { specified }\end{array}$ & $\begin{array}{l}168 \text { days } \\
\text { (estimated } \\
\text { from the text, } \\
\text { but not } \\
\text { specified) }\end{array}$ & $\begin{array}{l}\text { Not clearly specified } \\
\quad \text { for non-cardiac } \\
\text { adverse events } \\
0 \text { for cardiac adverse } \\
\text { events }\end{array}$ & $\begin{array}{l}6 \text { with }>60 \mathrm{~ms} \\
\text { increase (5 also } \\
\text { receiving CFZ) } \\
0 \text { with }>500 \mathrm{~ms}\end{array}$ & Not specified & Not specified \\
\hline $\begin{array}{l}\text { FerLazzo [14], } \\
\quad 2018\end{array}$ & $\begin{array}{r}\text { Armenia, South } \\
\text { Africa, India }\end{array}$ & $28(39 \%)$ & Not specified & $\begin{array}{l}2 \mathrm{MDR}(7 \%) \\
2 \mathrm{MDR}+\mathrm{INJ} \\
(7 \%) \\
10 \mathrm{MDR}+\mathrm{FLQS} \\
\text { resistant } \\
(36 \%)\end{array}$ & $14(50 \%)$ & $\begin{array}{l}0 \text { sequential } \\
28(100 \%) \\
\text { concomitant }\end{array}$ & $\begin{array}{l}17 \text { patients CFZ } \\
\quad(61 \%) \\
4 \mathrm{MFX}(14 \%) \\
2 \mathrm{CFZ}+\mathrm{MFX}(7 \%)\end{array}$ & $\begin{array}{l}\text { Occurred, but } \\
\text { it was not } \\
\text { specified }\end{array}$ & $\begin{array}{l}168 \text { days } \\
\text { lestimated } \\
\text { from the text, } \\
\text { but not } \\
\text { specified) }\end{array}$ & $\begin{array}{l}0 \text { for non-cardiac } \\
\text { adverse events } \\
0 \text { for cardiac adverse } \\
\text { events }\end{array}$ & $\begin{array}{l}4 \text { with }>60 \mathrm{~ms} \\
\quad \text { increase } \\
0 \text { with }>500 \mathrm{~ms}\end{array}$ & 17/23 (74\%) & $\begin{array}{l}22 \text { culture negative } \\
2 \text { culture positive } \\
1 \text { unable to } \\
\text { produce sputum } \\
1 \text { unclassified lonly } \\
\text { one sputum } \\
\text { culture negative) } \\
1 \text { lost to follow up } \\
\text { (while culture } \\
\text { positive) } \\
1 \text { died }\end{array}$ \\
\hline KIM [15], 2018 & South Korea & $11(39 \%)$ & $11(100 \%)$ & $7(63.6 \%)$ & $4(36.4 \%)$ & $\begin{array}{l}9 \text { sequential, BDQ } \\
\text { followed by } \\
\text { DLM } \\
1 \text { sequential, DLM } \\
\text { followed by } \\
\text { BDQ } \\
1 \text { concomitant }\end{array}$ & $\begin{array}{l}3 \text { FLQs (37\%) } \\
6 \text { CFZ (54.5\%) }\end{array}$ & $\begin{array}{l}\text { Occurred, but } \\
\text { it was not } \\
\text { specified }\end{array}$ & 168 days & $\begin{array}{l}0 \text { for non-cardiac } \\
\text { adverse events } \\
2 \text { (118.2\%) for cardiac } \\
\text { adverse events; one } \\
\text { case: concomitant } \\
\text { use; one case: } \\
\text { DLM-BDQ } \\
\text { sequential use (QTC } \\
\text { normalised after } \\
\text { discontinuation) }\end{array}$ & $\begin{array}{l}9(81.8 \%) \text { significant } \\
\text { prolongation } ; \\
\text { all patients had } \\
\text { at least one QTc } \\
\text { value }>460 \mathrm{msec}\end{array}$ & 7/7 (100\%) & $\begin{array}{l}\text { All } 7 \text { who were } \\
\text { culture positive } \\
\text { had culture } \\
\text { conversion }\end{array}$ \\
\hline $\begin{array}{l}\text { Total (range } \\
\text { 2016-2018) }\end{array}$ & & $\begin{array}{r}87(15 / 55 \\
27.3 \%)\end{array}$ & 17/17 (100\%) & $25 / 55(45.5 \%)$ & $30 / 55(54.5 \%)$ & $\begin{array}{l}14 / 55 \text { sequential } \\
\text { (25.5\%) } \\
41 / 55 \text { concomitant } \\
(74.5 \%)\end{array}$ & & 10/15 (66.7\%) & $\begin{array}{l}\text { Range (median } \\
\quad \text { values) } \\
168-171 \text { days }\end{array}$ & $\begin{array}{l}\text { 0/87 for non-cardiac } \\
\text { adverse events } \\
\text { 2/87 (2.3\%) for cardiac } \\
\text { adverse events }\end{array}$ & 23/87 (26.4\%) & $35 / 43(81.4 \%)$ & 10/14 cured (71.4\%) \\
\hline
\end{tabular}

\#: absolute value $>450 \mathrm{~ms}$ in men or $>470 \mathrm{~ms}$ in women (8 cases), or as a $>60 \mathrm{~ms}$ increase from baseline (3 cases). BDQ: bedaquiline; DLM: delamanid; FLQs: fluoroquinolones; RR: rifampin-resistant; INJ: injectables; CFZ: clofazimine; MFX: moxifloxacin; IQR: interquartile range. 
The keywords TB, delamanid and bedaquiline were used in different combinations. Two authors independently performed the search and evaluated titles and abstracts. The following variables were collected in suitable manuscripts: sputum smear and culture conversion, treatment outcomes, type of adverse events and their severity, demographics, mycobacterial drug resistance patterns, treatment regimens and their duration. The study was conducted following the 2009 PRISMA (Preferred Reporting Items for Systematic Reviews and Meta-Analysis) statement.

Out of the 126 identified articles, 119 were excluded because they did not report any information on the combined clinical use of the two drugs.

Seven studies [8, 10-15] met the inclusion criteria (one patient [10] was also described in the manuscript by Maryandyshev et al. [12] with additional information and, therefore, was counted only once in this review): two letters $[11,13]$ and four articles $[8,12,14,15]$ published between 2016 and 2018 have been included.

Overall, 87 adult cases were treated with delamanid and bedaquiline in Armenia, France, India, Latvia, Russian Federation, South Africa, South Korea and the Netherlands. DST results and HIV status were available in only 55/87 cases. More than half of those (30/55, 54.5\%) had XDR-TB [11-14] and 27.3\% (15/55) were HIV co-infected (with information available). All the cases with information provided on previous treatment (17/17) were re-treatment cases (table 1) [11, 12, 15].

Bedaquiline and delamanid were prescribed concomitantly and sequentially in 41/55 (74.5\%) and 14/55 cases, respectively [11-15]; one study did not specify (table 1) [8].

In sequential use, delamanid was started in 13 cases following the discontinuation of bedaquiline (range 1 -79 days); in one case only bedaquiline was started following the discontinuation of delamanid (1 day after). [13, 15]. In 10 out of 15 cases with information on this variable $(66.7 \%)$ bedaquiline and/or delamanid were prescribed for more than the recommended 24 weeks (6 months). In all cohorts, other QT-prolonging drugs were employed together with bedaquiline and/or delamanid (e.g. clofazimine and/or fluoroquinolones).

Out of 87 patients, 23 (26.4\%) showed $>1$ episode of QT prolongation $>450 \mathrm{~ms}$ in men or $470 \mathrm{~ms}$ in women, or a QT increase $>60 \mathrm{~ms}$ from baseline values. However, only $2 / 87$ (2.3\%) interrupted bedaquiline and/or delamanid for cardiac adverse events. The other adverse events reported in the various studies were rarely attributed to bedaquiline, delamanid or both [8,13-15]. Nevertheless, in most cases there were several confounding factors, such as co-administered anti-TB drugs and comorbidities, which make univocal attribution questionable [15].

Treatment outcomes were generally favourable considering the severity of these cases: sputum culture conversion was observed in the large majority of patients $(81.4 \% ; 35 / 43$ of those with available information) and a $71.4 \%$ success rate (cured patients: $10 / 14$ with information available) was obtained.

Details of the studies (adverse events and treatment outcomes) are summarised in table 1.

We systematically reviewed the available scientific evidence on the combined use of bedaquiline and delamanid in the management of MDR/XDR-TB cases.

Missing data could be found for four of the six studies that were not specifically designed to study safety and efficacy of bedaquiline and delamanid-containing regimens.

The main conclusions are the following:

1) Combined treatment is increasingly used to treat cases with intolerances, XDR-TB patients or other chronic patients with limited treatment options. Selection of this combination for each patient occurred in most cases after consultation of and approval by an "ad hoc" national/ international committee (National or International TB Consilia) [8, 11-15], while only a minority of cases were prescribed the two drugs exclusively by local clinicians (15 patients before September 2016).

2) The majority of patients were concomitantly treated with bedaquiline and delamanid, and a significant proportion of them were prescribed one or both drugs for $>6$ months.

3) Bedaquiline has a half-life of 5.5 months, in contrast with delamanid, which has a shorter half-life $(38 \mathrm{~h})$, leading to a potential co-administration when delamanid is prescribed sequentially after bedaquiline [15]. Evidence on additive or synergistic QT prolonging effects is lacking.

4) Only $2.3 \%$ interrupted for the occurrence of life-threatening cardiac adverse events [7].

5) Sputum culture conversion rate after 6 months of treatment was considerably higher (81.4\%) than historical MDR/XDR-TB patient cohorts [1]. 
6) Although the majority of patients are still on treatment, the $71.4 \%$ success rate found in the cases completing treatment is encouraging for future difficult-to-treat patients.

7) No published information is presently available on the combined use of delamanid and bedaquiline in children.

Due to the limited number of studies and patients evaluated, and relative information incompleteness, results should be evaluated cautiously. Well-designed experimental studies are imminently needed. However, reported data suggest that under specific conditions (e.g. quality-controlled laboratory, clinical expertise, monitoring capacity, support by TB consilia), combined treatment with bedaquiline and delamanid could be promising in chronic TB patients with limited therapeutic options.

Emanuele Pontali ${ }^{1}$, Giovanni Sotgiu $\odot^{2}$, Simon Tiberi $^{3,4}$, Marina Tadolini ${ }^{5}$, Dina Visca ${ }^{6}$, Lia D’Ambrosio $\odot^{7}$, Rosella Centis $\oplus^{6}$, Antonio Spanevello ${ }^{6,8}$ and Giovanni Battista Migliori $\oplus^{6}$

${ }^{1}$ Dept of Infectious Diseases, Galliera Hospital, Genoa, Italy. ${ }^{2}$ Clinical Epidemiology and Medical Statistics Unit, Dept of Clinical and Experimental Medicine, University of Sassari, Sassari, Italy. ${ }^{3}$ Blizard Institute, Barts and The London School of Medicine and Dentistry, Queen Mary University, London, UK. ${ }^{4}$ Division of Infection, Royal London Hospital, Barts Health NHS Trust, London, UK. ${ }^{5}$ Det of Medical and Surgical Sciences, Alma Mater Studiorum University of Bologna, Bologna, Italy. ${ }^{6}$ Istituti Clinici Scientifici Maugeri IRCCS, Tradate, Italy. ${ }^{7}$ Public Health Consulting Group, Lugano, Switzerland. ${ }^{8}$ Dept of Clinical and Experimental Medicine, University of Insubria, Varese, Italy.

Correspondence: Giovanni Battista Migliori, Istituti Clinici Scientifici Maugeri IRCCS, Via Maugeri 4, 27100, Pavia, Italy. E-mail: giovannibattista.migliori@icsmaugeri.it

Received: May 182018 | Accepted after revision: June 072018

Acknowledgements: This paper is part of the European Respiratory Society (ERS)/Latin American Society of Respiratory Medicine (ALAT) and ERS/Brazilian Society of Pulmonology (SBPT) collaborative projects, and of the operational research plan of the WHO Collaborating Centre for Tuberculosis and Lung Diseases, Tradate, ITA-80, 2017-2020GBM/RC/LDA.

Conflict of interest: E. Pontali has undertaken advisory board work for Janssen and Otsuka, outside the submitted work.

\section{References}

$1 \quad$ World Health Organization. Global Tuberculosis Report 2017. Geneva, World Health Organization, 2017.

2 Falzon D, Schünemann HJ, Harausz E, et al. World Health Organization treatment guidelines for drug-resistant tuberculosis, 2016 update. Eur Respir J 2017; 49: 1602308.

3 Borisov SE, Dheda K, Enwerem M, et al. Effectiveness and safety of bedaquiline-containing regimens in the treatment of multidrug and extensively drug-resistant tuberculosis: a multicentre study. Eur Respir J 2017; 49: 1700387.

4 Kuksa L, Barkane L, Hittel N, et al. Final treatment outcomes of multidrug and extensively drug-resistant tuberculosis patients in Latvia receiving delamanid-containing regimens. Eur Respir J 2017; 50: 1701105.

5 Pontali E, Sotgiu G, D'Ambrosio L, et al. Bedaquiline and MDR-TB: a systematic and critical analysis of the evidence. Eur Respir J 2016; 47: 394-402.

6 Pontali E, D’Ambrosio L, Centis R, et al. Multidrug-resistance tuberculosis and beyond: an updated analysis of the current evidence on bedaquiline. Eur Respir J 2017; 49: 1700146.

7 Pontali E, Sotgiu G, Tiberi S, et al. Cardiac safety of bedaquiline: a systematic and critical analysis of the evidence. Eur Respir J 2017; 50: 1701462.

8 Mohr E, Hughes J, Reuter A, et al. Delamanid for rifampicin-resistant tuberculosis: a retrospective study from South Africa. Eur Respir J 2018; 51: 1800017.

9 World Health Organization. WHO best-practice statement on the off-label use of bedaquiline and delamanid for the treatment of multidrug-resistant tuberculosis. WHO/HTM/TB/2017.20. Geneva, World Health Organization, 2017.

10 Tadolini M, Lingtsang RD, Tiberi S, et al. First case of extensively drug-resistant tuberculosis treated with both delamanid and bedaquiline. Eur Respir J 2016; 48: 935-938.

11 Lachâtre M, Rioux C, Le Dû D, et al. Bedaquiline plus delamanid for XDR tuberculosis. Lancet Infect Dis 2016; 16: 294.

12 Maryandyshev A, Pontali E, Tiberi S, et al. Bedaquiline and delamanid combination treatment of 5 patients with pulmonary extensively drug-resistant tuberculosis. Emerg Infect Dis 2017; 23: 1718-1721.

13 Guglielmetti L, Barkane L, Le Dû D, et al. Safety and efficacy of exposure to bedaquiline-delamanid in MDR-TB: a case series from France and Latvia. Eur Respir J. 2018; 51: 1702550.

14 Ferlazzo G, Mohr E, Laxmeshwar C, et al. Early safety and efficacy of the combination of bedaquiline and delamanid for the treatment of drug-resistant tuberculosis patients in Armenia, India and South Africa: a retrospective cohort study. Lancet Infect Dis. 2018; 18: 536-544.

15 Kim CT, Kim TO, Shin HJ, et al. Bedaquiline and delamanid for the treatment of multidrug-resistant tuberculosis: a multi-center cohort study in Korea. Eur Respir J 2018; 51: 1702467. 